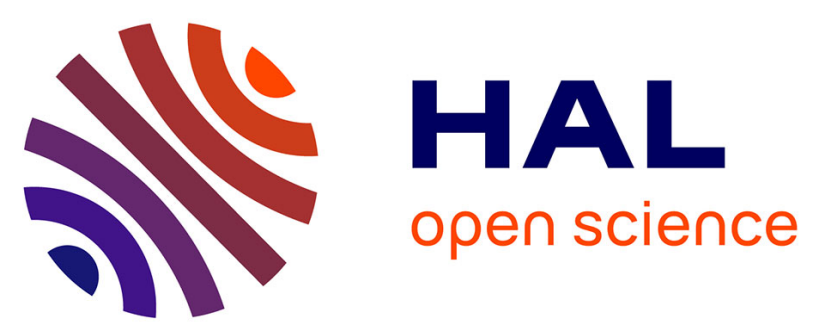

\title{
THE INTERACTION OF DISLOCATIONS AND A COHERENT TWIN BOUNDARY IN ORDERED Cu3AU AS STUDIED BY IN-SITU DEFORMATION IN A TEM
}

F. Tichelaar, F. Schapink

\section{To cite this version:}

F. Tichelaar, F. Schapink. THE INTERACTION OF DISLOCATIONS AND A COHERENT TWIN BOUNDARY IN ORDERED Cu3AU AS STUDIED BY IN-SITU DEFORMATION IN A TEM. Journal de Physique Colloques, 1990, 51 (C1), pp.C1-663-C1-668. 10.1051/jphyscol:19901105 . jpa00230012

\section{HAL Id: jpa-00230012 https://hal.science/jpa-00230012}

Submitted on 1 Jan 1990

HAL is a multi-disciplinary open access archive for the deposit and dissemination of scientific research documents, whether they are published or not. The documents may come from teaching and research institutions in France or abroad, or from public or private research centers.
L'archive ouverte pluridisciplinaire HAL, est destinée au dépôt et à la diffusion de documents scientifiques de niveau recherche, publiés ou non, émanant des établissements d'enseignement et de recherche français ou étrangers, des laboratoires publics ou privés. 


\author{
THE INTERACTION OF DISLOCATIONS AND A COHERENT TWIN BOUNDARY IN ORDERED \\ $\mathrm{Cu}_{3} \mathrm{AU}$ AS STUDIED BY IN-SITU DEFORMATION IN A TEM \\ F.D. TICHELAAR and F.W. SCHAPINK \\ Laboratory of Metallurgy, Delft University of Technology. \\ Rotterdamseweg 137, NL-2628 AL Delft, The Netherlands
}

\begin{abstract}
In order to investigate the microstructural behaviour of grain boundaries in $\mathrm{L}_{12}$-ordered $\mathrm{Cu}_{3} \mathrm{Au}$ during plastic deformation, in-situ deformation experiments were performed in a transmission electron microscope. The dislocation structure at a coherent twin boundary (CTB) before and after straining the specimen using a single-tilt straining holder is analysed in a doubletilt holder. During the in-situ deformation specific slip systems were active in both crystals from which dislocation transmission across the CTB was expected. However, the majority of the moving superdislocations are absorbed into the boundary, and change the boundary structure locally from a symmetrical structure into an asymmetrical one and vice versa. The implication is that grainboundary fracture might occur if larger strains are applied to the specimen for which experimental evidence is given.
\end{abstract}

1-INTRODUCTION. $\mathrm{L}_{2}$-ordered alloys like $\mathrm{Ni}_{3} \mathrm{Al}$ are known for their outstanding mechanical properties, especially at high temperatures. However, grain boundaries (GBs) in $\mathrm{L}_{1} 2_{\text {-ordered alloys }}$ often have a negative effect on the mechanical properties of such alloys $11 \%$ The brittleness of polycrystalline materials (e.g. $\mathrm{Ni}_{3} \mathrm{Al}$ ) finds its origin in both the specific grain-boundary structure and the manner in which the interaction of dislocations with GBs proceeds during plastic deformation. In-situ deformation experiments reported in the literature on polycrystalline $\mathrm{Ni}_{3} \mathrm{Al} / 2,3,4 /$ did not include a detailed analysis on the GB structure. Actually, experimental investigations on GB structure in $\mathrm{L}_{1} 2^{-}$ ordered alloys are rather scarce. MacKenzie, Vaudin and Sass $/ 5 /$ described a dislocation network in an artificially fabricated low-angle twist boundary in $\mathrm{Ni}_{3} \mathrm{Al}$. The present authors analysed coherent and incoherent twin boundaries in the model system $\mathrm{L}_{2}$-ordered $\mathrm{Cu}_{3} \mathrm{Au} / 6,7 /$. The interaction of dislocations with twin boundaries is of interest since many twin boundaries are present in $\mathrm{L}_{12}$-ordered alloys. For example, in $\mathrm{Ni}_{3} \mathrm{Al} 20 \% / 5 /$ to $50 \% / 8,9 /$ of the GBs are twin boundaries, depending on composition and annealing treatment.

In this paper results of an experimental study on the interaction of superdislocations with a coherent twin boundary (CTB) during in-situ deformation of ordered $\mathrm{Cu}_{3} \mathrm{Au}$ in a transmission electron microscope (TEM) will be described. A more elaborate paper on this experiment will be published elsewhere.

2-EXPERIMENTAL PROCEDURE. The preparation of $\mathrm{L}_{12}$-ordered $\mathrm{Cu}_{3} \mathrm{Au}$ specimens for TEM is described elsewhere $16,7 /$. The deformation experiment was executed as follows: First, an array of dislocations originating from a crack in the edge of the thin $\mathrm{Cu}_{3} \mathrm{Au}$ foil (see fig.2) which terminates in a CTB was selected. After analysing the boundary and the dislocations the specimen was transferred to a single-tilt straining holder with a mechanical drive. The specimen was clamped to the holder at two positions by copper blocks fastened by screws. Deformation proceeded very slowly at the region of 
(a)

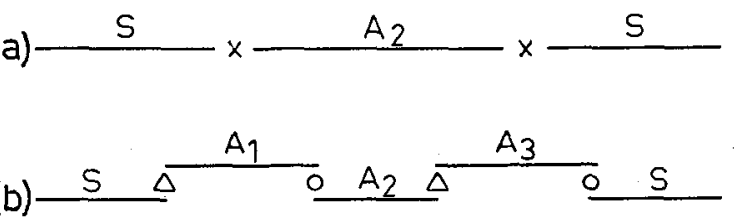

(c) $\stackrel{A_{2}}{-}$
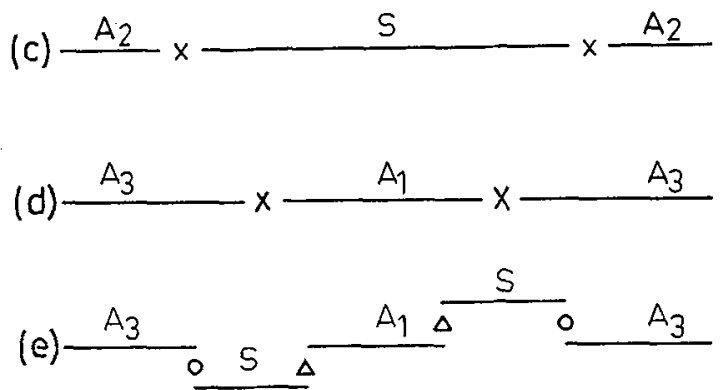

Figure 1 - Dissociation schemes of a glissile superdislocation absorbed into the S-structure of a (111) CTB in (a) and (b) and into the A-structure in (c), (d). and (e). Superpartials with $b=[101] / 2(x)$ can dissociate into Shockley partials with $b=[2 \overline{11}] / 6(\Delta)$ and $b=[112] / 6(0)$. Each boundary step equals $\pm[11 \overline{1}] / 3$.

interest, because most of the deformation during straining the specimen occurred elsewhere. Dislocation movement was followed by eye and electron micrographs were taken after each incremental strain. Subsequently the specimen was removed from the straining holder and placed back in the double-tilt holder for further analysis, using a Philips EM400T electron microscope.

3-STRUCTURES OF A CTB AND THE INTERACTION WITH GLISSILE SUPERDISLOCATIONS.The simple cubic lattice of the $L 12$-ordered $A_{3} B$ alloy is based upon the fCC lattice. The B atoms can occupy any of the four sc sublattices, and therefore four different domains exist. Antiphase boundaries (APBs) between domains are characterized by a translation (antiphase vector) of type $\mathrm{p}=<110>/ 2$. An APB which terminates in a CTB or a grain-boundary dislocation (GBD) with $b=<110>/ 2$ causes $a<110>/ 2$ translation of the two crystals relative to each other. This translation changes a symmetrical boundary structure (S-structure) into an asymmetrical structure (A-structure) $/ 6 /$, which is illustrated in fig. 1(a). The same structures may also be separated by a GBD of type $<112>/ 6$ $/ 6 /$,see fig.1(b). Three different variants of the A-structure exist; each variant corresponds to a different $<110>/ 2$ translation parallel to the $\{111\}$ boundary plane. Different variants of the same A-structure can be separated by a $<110>/ 2$ type dislocation or a terminating APB or a $<112>/ 6$ type dislocation. In the latter case a step is also introduced in the boundary plane, see fig.1(b).

When a pile-up of dislocations occurs at a GB, several possibilities exist to relieve the stress at the intersection of the pile-up and the GB as discussed by Shen, Wagoner and Clark /11/.Dislocations might be nucleated in the other crystal, while glissile residual GBDs of the DSC type are left behind. Alternatively dislocations are absorbed into the boundary and subsequent dissociation occurs into DSC dislocations which can move along the boundary plane. Transmission of dislocations is possible when the dislocations in both crystals have Burgers vectors parallel to a common direction. If none of such processes are possible GB fracture might occur.

In fig. 1 different dissociation schemes of a [110] glissile superdislocation absorbed into a (111) CTB are shown. The displacement-shift-complete lattice of the ordered structure $\left(\mathrm{DSC}^{\circ}\right)$ for this boundary is described by the shortest $\mathrm{DSC}^{\circ}$ vectors $1 / 3[11 \overline{1}] \mathrm{T}, 1 / 3[2 \overline{11}] \mathrm{T}$ and1/3[112]T. The subscript $\mathrm{T}$ refers to the twin crystal (if no subscript is present, the indices refer to the matrix (M)). In fig. 1(a) and (b) the absorbed superdiclocation changes the S-structure locally into A-structure. Fig.1(c),(d) and (e) are illustrations of superdislocations absorbed into different variants of the A-structure of the CTB. In fig. $1(\mathrm{c})$ a variant of the A-structure is changed into the $S$-structure, which is not the case in fig. $1(d)$. A subsequent dissociation of the GB superpartials into GB Shockley partials also changes the A-structure in fig. 1(d) into S-structure (fig.1(e)), which lowers the energy of the boundary. However, steps are introduced into the boundary plane. More dissociation schemes than illustrated in fig. 1 are geometrical possible /10/, but are not discussed here.

4-EXPERIMENTAL RESULTS AND DISCUSSION. The slip band originating from a crack in the edge of the thin foil shown in fig.2(a) terminates in the A-structure of a CTB, see fig.2(c). An array of superdislocations exists along the slip band in M. The superpartials are imaged separately in fig. 2(b), and the connecting APB between each pair of superpartials is visible in fig.2(c). Compare the fringes of those APBs to the thermal APB also visible. To our knowledge it is for the first time that the ribbon of APB between the superpartials forming a superdislocation in the $\mathrm{L}_{2}$ structure is imaged clearly. No 
(a)

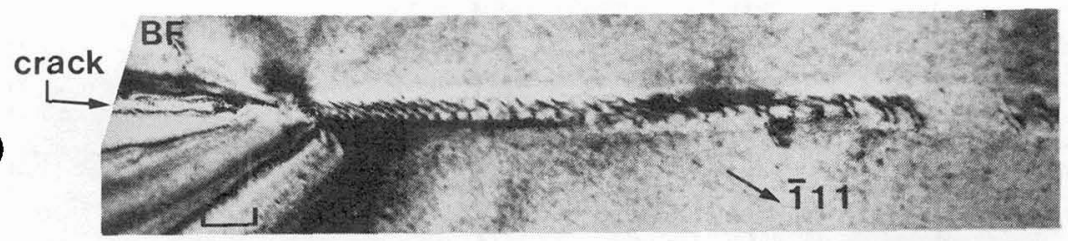

(b)

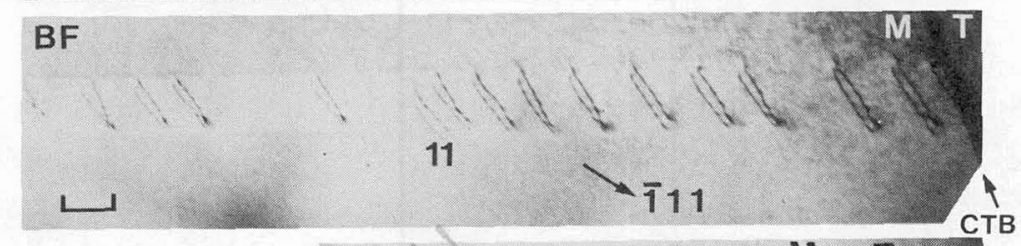

(c

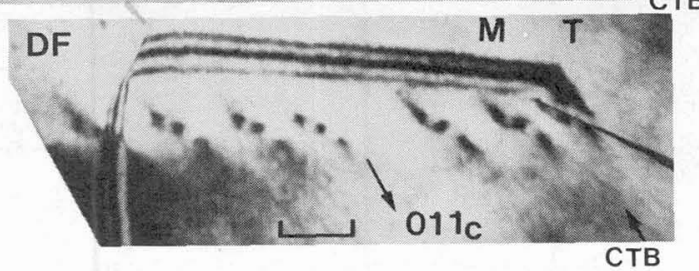

Figure 2 - Electron micrographs of a slip plane originating from a crack in the edge of the thin $\mathrm{Cu}_{3} \mathrm{Au}$ foil (a) and terminating in a CTB visible in (b). Micrographs (b) and (c) are of the same area employing a fundamental and a common superreflection respectively. Note the APB contrast in (c) between the superpartials imaged separately in (b). The scale markers indicate $100 \mathrm{~nm}$.

dislocations are present in the CTB or in T. The slip plane is (111) and the cross-slip plane of the superdislocations is (001). (For a discussion of cross-slip see /10/). Note that $\mathbf{b}$ and $\mathbf{u}$ of the superdislocations (see table) are parallel to the (111) boundary plane, and are common to $M$ and $T$ : $[110]_{\mathrm{M}}=[101]_{\mathrm{T}}$. Therefore, transmission of superdislocations is expected to occur during further deformation. The expected slipsystem in $T$ for transmission can be deduced from the maximalization of $M=\left(I_{M} \cdot I_{t}\right) \times\left(g_{m} \cdot g_{t}\right) / 11 /$, where $I_{M}$ and $I_{T}$ are the lines of intersection between the boundary plane and the slip planes in $M$ and $T$ respectively, and $g_{M}$ and $g_{T}$ are the slip directions in both crystals. From this geometrical criterion the expected slip system in T (111)[101]T follows.

The specimen was oriented in the deformation holder with the tensile axis $t_{\mathrm{a}}=[221] \mathrm{T}=[010] \mathrm{M}$. For this direction a maximal rss is obtained for the slip systems $(111)[1 \overline{10}]_{\mathrm{M}}$ and $(\overline{111})[101] \mathrm{T}$. However, the right value of $t_{a}$ near the area of interest cannot be predicted because of the complicated specimen geometry and inhomogeneous stress concentrations in the thin foil.

During the first stages of deformation nothing happened in the area with the sessile superdislocations (fig.2(b)), but superdislocations moved in T on parallel slip planes towards the CTB in the direction of the arrow in fig. 3(a). In fig.3(a) and (b) micrographs of the CTB are shown, which were taken after two incremental strains applied to the specimen. The area shown in fig. 3 is above the area shown in fig. 2 along the same CTB. In fig.3(a) several pairs of dislocations are visible in the boundary, which all moved as pairs in $T$ towards the boundary during the in-situ deformation. At position 2 one of the dislocations forming a pair is present in $M$.After an additional strain the superdislocation present at position 3 has moved to position 2, see fig.3(b). When the electron beam was focussed at position 2 one of the dislocation pairs moved slowly into $M$, and is still visible in $M$ in fig.3(b). The superdislocation at position 4 did not move during the in-situ straining. This superdislocation has probably undergone cross-slip to the sessile cube plane : the line between the intersections of both superpartials forming the superdislocation with the foil surface is not parallel to the slip direction indicated by the arrow in fig.3(b). When the strain increased eventually slow dislocation movement was observed along the slip band in $M$ (fig.2) towards the CTB. It appeared the dislocations already present were passed by the moving dislocations on a parallel slip plane. From the intersection of the slip plane in $M$ and the CTB some dislocations were seen to move slowly into $T$.

In fig. 4 an image of the slip band in $M$ is shown, taken after the specimen was removed from the straining holder and placed into the double-tilt holder. The positions of the dislocations along the slip band can all be correlated to the positions of the dislocations before deformation occurred (cf position 


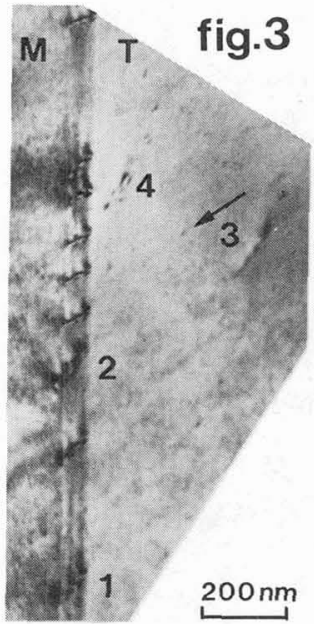

(a)

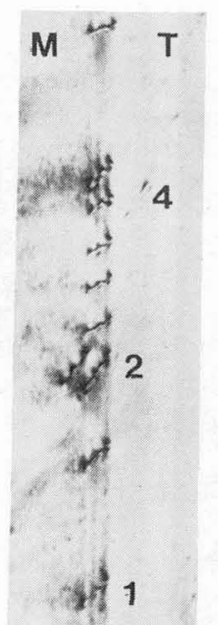

(b)

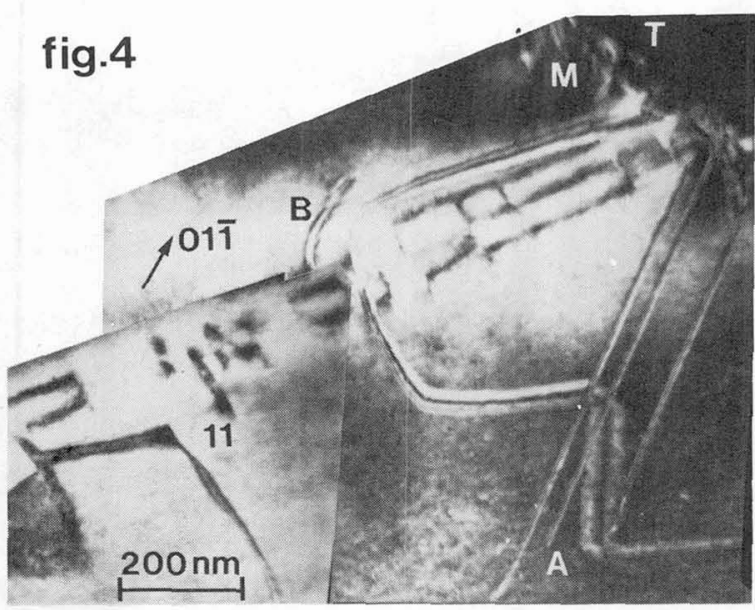

Fiqure 3 - Bright-field electron micrographs of the same area showing the CTB vertically. Corresponding positions are numbered. The strain on the specimen was increased between (a) and (b). As a consequence the superdislocation at 3 moved in the direction of the arrow into the boundary at 2 , and the superdislocation already present at 2 moved into $M$ when the electron beam was focussed upon it.

Figure 4 - Dark field electron micrograph employing a superreflection of the slip band in $M$ after the in-situ deformation experiment. Position 11 is also indicated in fig.2. APB contrast is visible along the larger part of the slip band. At position A superpartials connected to APBs caused by slip are visible.

11 in fig.2 and fig.4). However the superpartial separation is irregular now, and APB contrast is visible along a large portion of the slip band. This means some dislocations moved as single superpartials along the slip band. At position A in fig.4 three superpartials are visible connected to APBs caused by slip. Dislocations $A$ and $B$ are of a type different from the dislocations along the slip band (see table) and were generated during specimen handling. In fig. 5 dislocations in T near the intersection of the slip

(a)

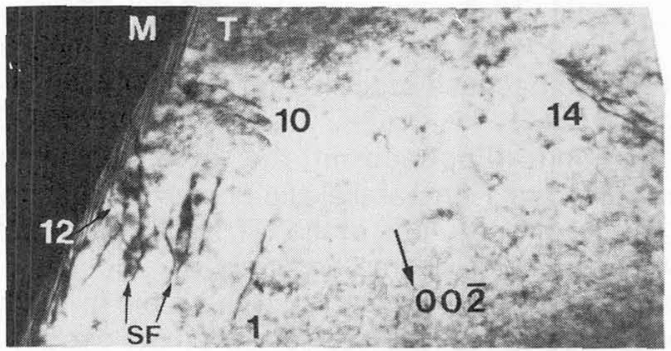

(c)

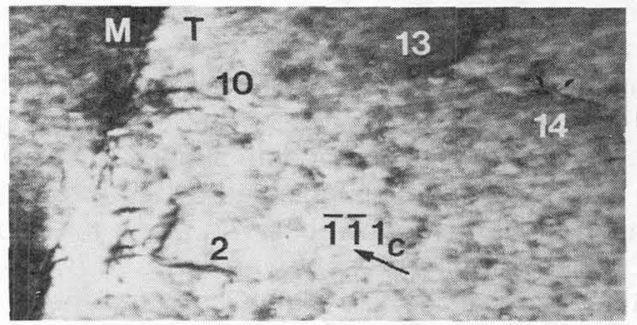

(b)

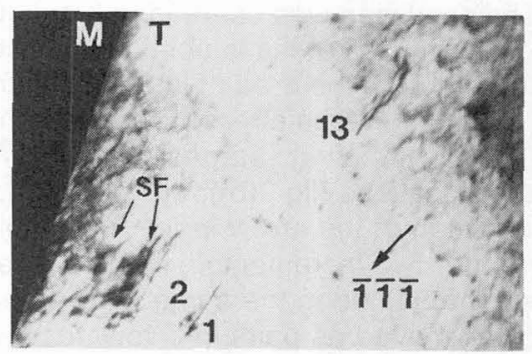

(d)

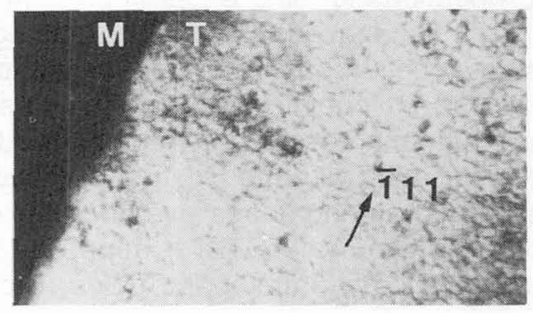

Figure 5 - Dark-field electron micrographs of the same area in T near the intersection of the slip band shown in fig. 2 and 4 and the CTB. Several dislocations are numbered and two narrow stacking faults are indicated in (a) and (b). 
(a)

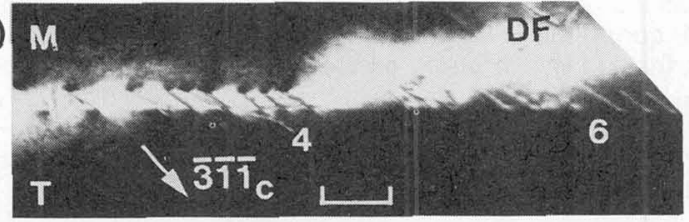

(c)

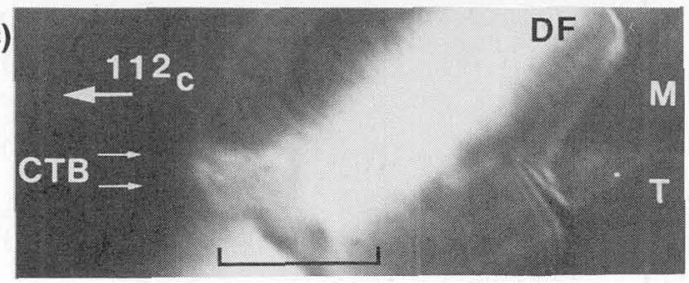

(b) $\mathrm{M}$

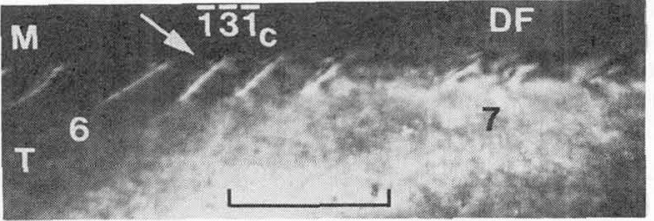

(d)

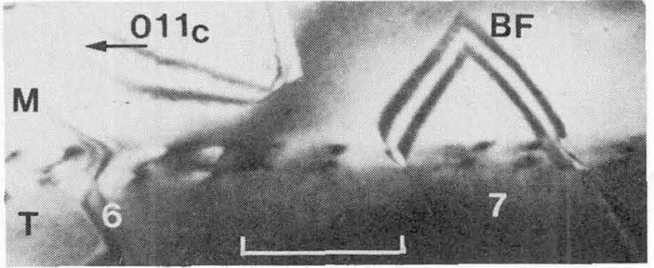

Figure 6 - Electron micrographs of approximately the same area along the CTB employing common fundamental reflections in (a) and (b) and common superreflections in (c) and (d). Corresponding positions are indicated by numbers 6 and 7. Each pair of dislocations absorbed into the boundary (b) bounds a ribbon of A-structure in the CTB with S-structure. This structure is visible in (d) as fringes similar to APB contrast. The scale markers indicate $200 \mathrm{~nm}$.

band in $M$ and the CTB are shown. Most of them were generated during the in-situ deformation and were seen to move in a direction consistent with the slip plane deduced from the edge-on position in fig.5(d). APB contrast connected to the dislocations (not shown here) implies they are single superpartials. Other dislocations are present too, and were generated when the specimen was placed in the double-tilt holder for analysis (see table). In fig.5(a) and (b) stacking fault contrast is visible along two narrow ribbons. The nature of these faults could not be determined. Elsewhere in the specimen a

SISF and a CSF, both connected to APBs caused by slip were present, see $110 /$. In the twin boundary many dislocations are present (see fig. 5 (a)) which are of the same type as the dislocations in $M$ along the slip band. In fig. 6(a) and (b) dislocation pairs in the CTB are shown which originated from T during the in-situ straining experiment. Position 4 in fig. 6.(a) corresponds to position 4 in fig.3. Some additional dislocation pairs are present in the boundary after deformation as shown in fig.6 compared to fig.3. Analysis of the GBDs showed each pair is a superdislocation absorbed into the S-structure of the CTB as illustrated in fig.1(a). Fig.1(d) shows the A-structure in the boundary between the superpartials forming one pair. The Burgers vector of the absorbed superpartials was determined from the invisibility criterion $g_{c} \cdot b=0$, where $g_{c}$ is a common reflection, and from $g \cdot b=0$, when only one crystal is diffracting strongly (see table). It should be mentioned the latter criterion is not valid when the GBDs are of edge character /12/. The (111)T slip plane of the GBDs prior to the absorption in the CTB was derived from the direction of the slip traces in T. The GBDs did not move during the in-situ deformation as soon as they were absorbed into the S-structure. However, a movement of one dislocation pair absorbed into the A-structure (cf. fig. 1 (c)) was observed /10/. The separation distance of the superpartials in this particular case was larger than the separation distance of the superdislocations in the S-structure. This is expected, since a widening of the superpartials changes part of the boundary area from an Astructure into the S-structure, which lowers the total energy of the boundary.

All dislocation movements during the in-situ straining experiment (denoted by * in the table) belonged to the slip system (111)[110] $\mathrm{M}$ in $\mathrm{M}$ and (111)[101] $\mathrm{T}$ in $\mathrm{T}$. All other dislocations were generated when the specimen was removed from the straining holder into the double-tilt holder. Therefore, the assumption of uniaxial deformation is applied to the region of interest, and transmission of superdislocations across the CTB is expected as discussed above. However, absorption of superdislocations into the boundary is observed for most of the dislocations. The absorption process can be regarded as a cross-slip event from the (111)[101]T glide plane onto the (111) CTB plane, and is not a consequence of a large rss on the boundary plane $/ 10 /$. The driving force for this absorption event is presumably the lower energy of the superdislocation in the S-structure as compared to the energy of the superdislocation in the bulk, since the self energy of the superpartials is lower in the GB /13/. The separation distance of the superpartials in the boundary is $120 \AA$, the same as for a superdislocation in the bulk $/ 14 /$, and the energy of the A-structure relative to the S-structure is the same as for an APB if only nearest neighbours and second-nearest neighbours are taken into account, see $/ 10 /$. 
Burgersvectors $\mathbf{b}$ and line directions $\mathbf{u}$ of various dislocations analysed after the in-situ straining experiment. The symbol * denotes dislocations which were generated during the in-situ deformation. The other dislocations were generated during specimen handling; $n$ denotes the $\{111\}$ slip plane or the $\{100\}$ habit plane of the dislocations.

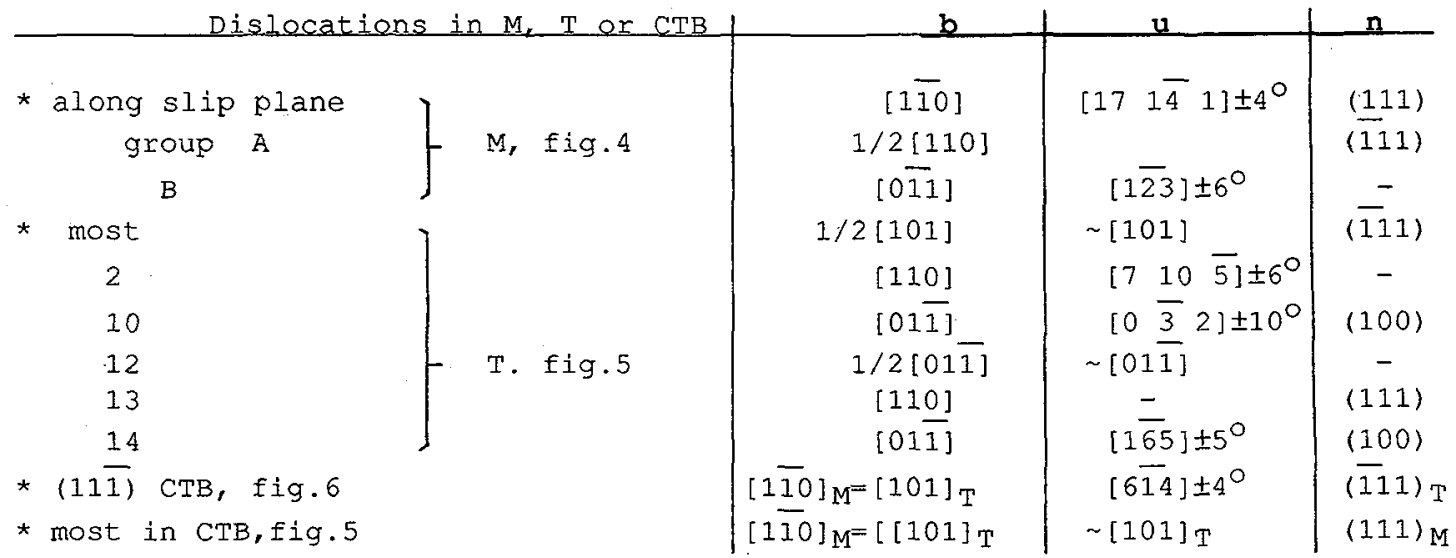

The orientation relationship between $M$ and $T$ has been changed by the absorption of the screw superdislocations. The extra rotation was measured at position 6 in fig. 6 by the shift of Kikuchi-lines in T relative to $M$ using common reflections as $0.7^{\circ} \pm 0.1^{\circ}$ around the rotation axis $[\overline{3} \overline{2} \overline{6}$ (with an accuracy of 100). Also, long-range stresses are introduced by the array of screw dislocations, which means the CTB cannot act as a sink for screw-type superdislocations when deformation continues. Eventually some mechanism must relieve the accumulated stress when more and more dislocations are absorbed into the CTB. Whether this mechanism will be GB fracture or emission in the second crystal is difficult to predict : at the intersection of the slip band in $M$ and the CTB many dislocations arrived at the same position at the boundary from $M$ of which the majority was absorbed in the boundary (fig.6(a)) while the transmitted dislocations were at least partly single superpartials leaving behind a ribbon of APB which impedes dislocation motion. Further experiments have to be carried out to see how deformation proceeds with increasing strain.

\section{REFERENCES}

/1/ Pope, D.P., Mat. Res. Soc. Symp. Proc. 81 (1987) 3.

12/ Baker, I., Schulson, E.M., and Horton, J.A., Acta metall. 35 (1987) 1533.

13/ Bond, G.M., Robertson, I.M., and Birnbaum, H.K., J. Mater, Res.2 (1987) 436.

/4/ Bond, G.M., Robertson, I.M., and Birnbaum, H.K., Acta metall. 37 (1989) 1407.

15/ MacKenzie, R.A.D., Vaudin, M.D., and Sass, S.L., J. de Physique Coll. 49 (1988) C5-227

16/ Tichelaar, F.D., and Schapink, F.W., Phil. Mag. A54 (1986) L55

7/ Tichelaar, F.D., and Schapink, F.W., J de Physique coll. 49 (1988) C5-293.

18/ Farkas, D.,Lewus, M.O., and Rangarajan V., Scr. Metall. 22 (1988) 1195.

19/ Swiatnicki, W.A., and Grabski, M.W., Acta metall. 37 (1989) 1307.

/10/ Tichelaar, F.D., and Schapink, F.W., to be published.

/11/ Shen, Z.,Wagoner, R.H., and Clark, W.A.T., Acta Metall. 36 (1988) 3231.

/12/ Marukaura, K., and Matsubara, Y., Trans. JiM 20 (1979) $560 ; 724$.

/13/Priester, L., Les joints de grains dans les materiaux, edited by M. Aucouturier (Les editions de Physique) 1984

/14/ Sastry, S.M.L., and Ramawami, B., Phil. Mag. 32 (1976) 801. 